\title{
Floración algal nociva. Marea roja
}

Desde tiempos inmemorables el hombre ha sido testigo de los cambios que suceden en su lugar de origen, el mar. La Floración Algal Nociva (FAN) o Marea Roja esta distribuida a todo lo largo del planeta y en las costas de nuestro país no ha sido la excepción, la zona pacifica ha sido la mas afectada, hay reportes desde hace unos siglos, sin embargo ha sido mas notoria hace unas décadas hasta el presente, esto muy en relación a los cambios climáticos que el planeta esta sufriendo y que los científicos achacan a los cambios de temperatura, acidez, y flujo de corrientes que ha traído entre otras cosa el calentamiento del planeta, llevando al fenómenos del Niño . Estos microorganismos llamados dinoflagelados, por su aspecto de flagellum (látigo) son los causantes de la intoxicación que sufrimos los mamíferos al comer la carne contaminada, sobretodo a nivel del aparato gastrointestinal de los mariscos (cierto tipo de ellos, los bivalvos) dicha toxina se encuentran entre las más letales, hay diferentes característica de pigmentación de la costa, sea roja, naranja, ocre etc, aun más las menos llamativas en ocasiones traen mayor cantidad de microorganismos, la cantidad es variable pero va de 2 millones a 36 millones por litro y su numero determina un alto consumo de oxigeno en las aguas costeras llevando a la muerte a muchos peces por este mecanismo y sus toxinas.

La toxicidad en el humano lo da directamente una toxina, como la saxitocina o la brevetoxina, alterando el paso del $\mathrm{Na}$ en los canales celulares semejante a patología medicas de los canales de $\mathrm{Na}^{2}$ que conlleva a trastornos de la conducción nerviosa entre otros. Las patología mas frecuentes lo serán $\mathrm{La}$ intoxicación por mariscos a saber: paralítica, neurotoxica, diarreica y amnésica, la mas importante de ellas lo será la paralítica ya que es causal de mortalidad entre un 6 y $12 \%$, según reportes, dichosamente en $\mathrm{CR}$ no hemos tenido muertes al momento, pero si casos que ameritaron la ventilación mecánica, su clínica es de luego de un periodo que va de $30 \mathrm{mi}-$ nutos hasta casi 3 horas de ingerido el bivalvo, datos de parestesias en boca cara cuello, así como la sensación de parestesias en guante y calcetín en las extremidades como se vio en el año $89-90{ }^{3}$ y en el 2001 en Liberia donde también hubo casos de paro respiratorio, se manejaron un total de casi 39 pacientes con estas mismas características ${ }^{4}$.

En su diagnóstico tenemos problemas ya que la metodología actual basada en las unidades ratón podría dar margen de error, en algunas zonas de América hay métodos diagnósticos más efectivos como es el caso de Chile donde se cuenta con anticuerpos monoclonales.
Para desgracia nuestra no hay antídoto para dichas toxinas, así que su manejo es de soporte, pero lo mas importante es hace una adecuada prevención y tener la capaciđad suficiente para dar apoyo y sostén a las familias que se afectan por la veda, generando ello un problema social de gran magnitud. Desde el punto de vista médico nuestra responsabilidad es educar a las personas para evitar accidentes. Los médicos tendrán un excelente revisión en el artículo publicado por los autores Freer y Vargas donde se tocan en forma amplia y clara todas las patologías asociadas a la FAN.

\section{Referencias}

1. Patricia Ramírez. Qué es el fenómeno de El Niño-Oscilación del Sur (ENSO) http//nimbus.efis.ucr.ac.cr/meteo/documentos/enos.html El fenómeno del Niño http//ekeko.rcp.net.pe/cepes-el-nino/l-porque.htm

2. Grant A. Molecular biology of sodium channels and their role in cardiac arrhythmias. Am J Med 2001: 110: 296-305

3. Mata L, Abarca G, Marrangello L. Víquez R. Envenenamiento paralítico por Spondylus calcifer contaminada por Pyrodinium bahamense, Costa Rica, 1989-1990; 38: 129-36.

4. Rosales et al. En prensa. Comunicación personal.
Dr. Francisco Jiménez Bolaños. Especialista en Medicina Interna y Medicina de Emergencias. Hospital México. 